\title{
Microscale distribution patterns of terrestrial bryophytes in a subalpine forest: the use of logistic regression as an interpretive tool
}

\author{
K. D. Sadler and G. E. Bradfield \\ Department of Botany, University of British Columbia, 6270 University Blvd. Vancouver, \\ BC Canada,V6T 1Z4; E-mail: kella@mail.botany.ubc.ca,garyb@interchange.ubc.ca.
}

Key words: Bryophyte, Community pattern, Facilitation, Logistic regression, Microhabitat, Multivariate analysis, Subalpine forest.

Abstract: This study investigated microhabitat relationships of terrestrial bryophytes in a subalpine forest of coastal British Columbia. Substratum affinities were characterized for dominant bryophytes. Logistic regression analysis was used to gain insight into the ecological determinants of fine scale $\left(0.1 \mathrm{~m}^{2}\right)$ bryophyte distribution by examining the predictive relationship between bryophyte species occurrence and localized environmental conditions, as well as the coverage of other bryophytes. The predictive relationships were compared to evaluate the relative importance of environmental factors versus interspecific interactions in structuring bryophyte communities. The results indicate that bryophytes show unique responses in their relationships to environmental conditions and other bryophytes. Positive feedback appears to be an important process among terrestrial bryophytes in subalpine forests.

Nomenclature: Lawton (1971) for mosses; Godfrey (1977) for liverworts; Hitchcock and Cronquist (1973) for vascular plants.

Abbreviations: CRS - Creeping Stem; EXH - Exposed Humus; FLI - Fine Litter; LFH - The accumulation of organic material present over mineral soil (Litter, Fermentation and Humus); LR - Logistic regression; WOOD - Woody Debris.

\section{Introduction}

Bryophyte distribution patterns on a fine scale are likely to be strongly influenced by microscale variation in substratum, neighbouring bryophytes, and other small scale habitat features (Carleton 1990). Previous studies have demonstrated the sensitivity of bryophytes to changes in microhabitat conditions (Kenkel and Bradfield 1986, Soderstrom 1993, Řkland 1994, McAlister 1995, Peck et al. 1995, Rambo and Muir 1998). Limited microscale ecological information exists for bryophytes in the coniferous forests of Pacific North America, and most of this is contained in floristic works (e.g., Lawton 1971, Schofield 1976, Godfrey 1977) and field guides (Vitt et al. 1988, Schofield 1992). Subalpine forests have been particularly underrepresented in bryophyte research. As subalpine forests face increasing pressures from recreational use and logging, more research is required to sustain high bryophyte species diversity in these fragile ecosystems.
A limitation in describing microscale bryophyte-environment relationships is that most statistical techniques inadequately convey information at the species scale. Ordination techniques, most commonly used to identify environmental gradients correlated with compositional change in plant communities (Gauch 1982), are limited in this way. As an alternative to ordination, logistic regression (LR) may be used when interest focuses directly on the responses of particular species to environmental factors. Because logistic regression analysis employs mixtures of continuous and discrete variables (e.g., microhabitat variables) to predict a discrete outcome in a response variable (e.g., presence or absence of a given species), more detailed ecological questions can be addressed than by using standard regression and ordination methods (Trexler and Travis 1993, Tabachnick and Fidell 1996).

In addition to answering specific questions regarding microscale distributions, LR may be a more statistically appropriate technique to use when data do not meet the 
assumptions of other approaches. For example, whereas ordination methods may assume linearity (principal component analysis), or unimodality (correspondence analysis) in the responses of species to underlying gradients, LR makes no such assumptions and requires only that response variables have minimum frequency (usually $>5 \%$ ) in relation to categories of predictor variables (Tabachnick and Fidell 1996). Owing to its lack of reliance on statistical assumptions, LR could find wide application in ecology (Trexler and Travis 1993). To date, however, few applications of LR have appeared in the plant ecological literature (e.g., van de Rijit et al. 1996).

The objective of this study was to describe the microscale habitat relationships of terrestrial bryophytes in a subalpine forest of coastal British Columbia. Logistic regression was used to investigate the predictability of occurrence of bryophyte species in particular environmental conditions, and in associations with other bryophytes. The results provide insight into the ecological determinants of bryophyte distribution on a fine scale, and allow for the evaluation of LR as a technique for interpreting such relationships.

\section{Methods}

\section{Study area and field sampling}

The study area is located in unlogged, old-growth subalpine forest in the Coast Mountains near Vancouver, British Columbia. The prevailing climate is characterized by cool short summers, and long, cold, wet winters with deep snow accumulation over unfrozen ground for up to ten months each year (Pojar et al. 1991). The forest canopy is comprised of Tsuga mertensiana, Abies amabilis, and Chamaecyparis nootkatensis, and prominent understory shrubs include Vaccinium alaskaense, V. membranaceum, Menziesia ferruginea, Rhododendron albiflorum, and Rubus pedatus. The terrestrial bryophyte layer is generally well-developed and comprises several species of mosses and liverworts. The mosses Rhytidiopsis robusta and Dicranum pallidisetum are common in many areas.

Forty-five $20 \mathrm{~m} \times 20 \mathrm{~m}$ plots, ranging in elevation from $1100 \mathrm{~m}$ to $1300 \mathrm{~m}$ a.s.1., were systematically established at $50 \mathrm{~m}$ intervals along a series of transect lines in undisturbed forest. Within each plot, eight $0.1 \mathrm{~m}^{2}$ microplots were systematically sampled along perpendicular transects intersecting at the plot center. This sampling design creates a data bias toward the plot center; however, it allowed optimum placement of microplots for examining contour related effects on bryophyte distributions. In total, 360 microplots were sampled.
Environmental measurements recorded at the plot scale $\left(400 \mathrm{~m}^{2}\right)$ included landscape features (slope, aspect), and soil characteristics determined from a soil pit excavated near the plot center. Depth of the litter layer (LFH) was recorded in the field. Subsequent laboratory analysis of the soil samples yielded plot values for $\mathrm{pH}$, organic matter content (loss on ignition method), and total Kjeldahl nitrogen (Carter 1993). For the purpose of data analysis the estimates of carbon and nitrogen were combined into a $\mathrm{C}: \mathrm{N}$ ratio for each plot.

Environmental measurements at the microplot scale included canopy cover (measured with a spherical densiometer), and the total percent coverage and maximum height of understory vascular plants, irrespective of species. As well, the total numbers of vascular plant species and conifer seedlings (by species) in microplots were noted. The environmental conditions measured at the plot scale appeared to remain relatively constant within plots; therefore, these measurements were applied to all microplots within each plot.

Total bryophyte cover within microplots was estimated, as was the coverage of separate bryophyte species on each of four substratum-types: fine litter (FLI, consisting of conifer needles and woody debris $<1 \mathrm{~cm}$ in width), fallen branches and tree stems (WOOD, comprising woody debris $1-10 \mathrm{~cm}$ in width), exposed humus (EXH, including decayed, compacted organic material with no buildup of fine litter or woody debris), and creeping stems (CRS, consisting of stems and branches of vascular plants lying close $(<5 \mathrm{~cm})$ to the ground surface). Also recorded was the total cover (i.e., availability) of each of the four substratum-types within microplots.

Two features of the sampling design used warrant some concern: first, the treatment of microplots as replicates in this analysis may have introduced problems with spatial autocorrelation, particularly since bryophyte distributions are often patchy; second, the inference that some plot variables (i.e., aspect, slope, LFH characteristics) are constant at the microplot level may not be valid in all situations. In light of these concerns, the precise levels of significance associated with the LR results should be viewed with caution.

\section{Data analysis}

Logistic regression models produced large parameter estimates and standard errors, or failed to converge, for species with less than $5 \%$ occurrence in microplots. In consequence, only those bryophytes with greater than $5 \%$ frequency were included in further analyses. Of the 42 species of mosses and liverworts identified during sam- 
pling, 14 species met this requirement. To facilitate interpretation of bryophyte-substratum affinities, the frequencies of these 14 bryophytes on the four main sub- stratumtypes were calculated as the number of microplots in which a species occurred on a particular substratum divided by the total number of microplots containing that substratum.

To investigate the relationship between bryophyte species occurrences and microplot conditions, two types of logistic regression were performed on each species: one using the environmental variables (landscape, soil, vascular plant cover and species richness, substratum availability) as predictors, and one using the coverages of the other 13 bryophyte species as predictors.

Although LR is free of parametric restrictions, and can analyze a mixture of types of predictors (continuous, discrete, and dichotomous), it is required that the outcome variable be discrete (in this case, the presence or absence of bryophytes). Also, the method requires an adequate ratio of cases to variables; it is recommended that $N \geq 50+$ $80 m$ (where $N=$ sample size, and $m=$ number of independent variables) for testing regression, and $N \geq 104+m$ for testing individual predictors (Tabachnick and Fidell 1996). These recommendations were met for the LR analyses in this study. Moreover, LR is sensitive to high correlations among predictor variables (multicollinearity), and can be influenced by outliers. Fine litter (FLI) was not used as a predictor variable in the environmental LRs because of its strong negative correlation with the availability of woody debris (WOOD).

The goal of logistic regression is to find the best linear combination of predictors to maximize the likelihood of obtaining the observed outcome frequencies. The linear regression equation is the natural log of the probability of being in one group divided by the probability of being in the other group. LR predictions take the form of a probability $p$ ranging from 0 and 1 ; the probabilities are calculated using maximum likelihood estimation. Classification is usually accomplished by rounding the $p$ value to the nearest integer (either 0 or 1 ).

All LR analyses in this study employed the LOGIT program of SYSTAT® Version 8.0 (SPSS Inc. 1998). Models were tested in a direct (rather than stepwise) fashion. Wald's statistics were used to indicate the importance of individual microhabitat variables in predicting the presence or absence of a bryophyte species. The sign of the logit coefficients suggested whether a species was more likely (positive sign) or less likely (negative sign) to occur given a change in a microhabitat variable.
Rho-squared values (analogous to $\mathrm{R}^{2}$-values in multiple regression) were used to characterize the overall strength of the relationships between bryophyte presence/absence and the set of microhabitat (environment or bryophyte) predictor variables. According to Tabachnick and Fidell (1996), rho-squared values greater than 0.2 indicate a satisfactory relationship between predictor and response variables in LR. All results were adjusted using the quasi-maximum likelihood procedure (a component of the SYSTAT ${ }^{\circledR}$ LOGIT program), which corrects covariance problems in models.

\section{Results and discussion}

\section{Substratum frequencies}

Table 1 shows the percent frequencies of bryophytes recorded on the four main substratum-types. In general, mosses occur with higher frequencies than liverworts on fine litter (FLI). Liverwort species occur mainly on exposed humus (EXH), a prominent substratum-type in closed-canopy habitats that have a build-up of undecomposed organic material. Pseudoleskea baileyi is the only species that occurs primarily on the creeping stems of vascular plants. The mosses Hypnum circinale and Rhytidiopsis robusta, and the liverwort Ptilidium californicum, show relatively wide tolerance ranges, occurring on each of the four substratum-types with at least $5 \%$ frequency.

Although this information increases our understanding of the occurrence of bryophyte species in subalpine forests, substratum affinity is only one mechanism that may influence the presence or absence of species. For example, species occurrence may be more related to a particular set of environmental conditions than the availability of a certain substratum when that substratum is widely available in different habitats. Furthermore, the occurrence of a bryophyte species may be related to the presence, absence, or coverage of other bryophyte species.

\section{Microscale prediction of bryophyte species occurrence}

The predictive relationships of bryophyte species with environmental factors and coverages of other bryophytes in microplots are summarised in Tables 2 and 3, respectively. The results indicate substantial differences among species in the predictability of occurrence from environmental factors and the coverage of other bryophytes. The differing response patterns reveal habitat features which may be of interest in more detailed autecological studies. Among the environmental variables, exposed humus availability is a positive predictor for five of the eight liverwort species analyzed, suggesting that it is an important environmental factor contributing to bryophyte diversity. 
Table 1. Percent frequencies of mosses and liverworts with $>5 \% *$ microplot frequency ( $\mathrm{n}$ is the total number of microplots in which the species occurred) on fine litter (FLI), woody debris(WOOD), exposed humus (EXH), and creeping stem (CRS) substratum-types in relation to the total number of microplots containing each substratum-type (shown at the top of each column).

\begin{tabular}{|c|c|c|c|c|c|c|}
\hline Code & Mosses & $\mathbf{n}$ & $\begin{array}{c}\text { FLI } \\
(\mathbf{3 6 0})\end{array}$ & $\begin{array}{c}\text { WOOD } \\
(\mathbf{3 0 3})\end{array}$ & $\begin{array}{c}\text { EXH } \\
(71)\end{array}$ & $\begin{array}{l}\text { CRS } \\
(50)\end{array}$ \\
\hline Braclei & Brachythecium leibergii & 25 & 5.8 & 0.7 & 5.6 & 2.0 \\
\hline Dicrpal & Dicranum palledisetum & 254 & 62.2 & 9.6 & 39.4 & 4.0 \\
\hline Hypncir & Hypnum circinale & 74 & 12.8 & 6.9 & 23.9 & 2.0 \\
\hline Plaglae & Plagiothecium laetum & 94 & 15.0 & 7.9 & 33.8 & 2.0 \\
\hline Pseubai & Pseudoleskea baileyi & 64 & 13.6 & 4.6 & 4.2 & 42.0 \\
\hline Rhytrob & Rhytidiopsis robusta & 217 & 59.7 & 6.9 & 16.9 & 12.0 \\
\hline \multicolumn{3}{|c|}{ Average Frequency (Mosses): } & 28.2 & 6.1 & 20.7 & 10.7 \\
\hline Code & Liverworts & & & & & \\
\hline Barbflo & Barbilophozia floerkei & 33 & 8.3 & 1.0 & 2.8 & 0.0 \\
\hline Bleptri & Blepharostoma trichophyllum & 35 & 2.8 & 3.3 & 25.4 & 0.0 \\
\hline Calymue & Calypogeia muelleriana & 47 & 7.5 & 2.6 & 22.5 & 0.0 \\
\hline Cephlun & Cephalozia lunulifolia & 49 & 4.4 & 5.0 & 31.0 & 2.0 \\
\hline Dipltax & Diplophyllum taxifolium & 18 & 3.9 & 0.3 & 5.6 & 0.0 \\
\hline Lophhet & Lophocolea heterophylla & 100 & 13.9 & 9.6 & 42.3 & 4.0 \\
\hline Lophgut & Lophozia guttulata & 35 & 5.8 & 3.6 & 11.3 & 2.0 \\
\hline Ptilcal & Ptilidium californicum & 125 & 13.3 & 22.8 & 19.7 & 28.0 \\
\hline \multicolumn{3}{|c|}{ Average Frequency (Liverworts): } & 8.3 & 8.3 & 22.0 & 7.2 \\
\hline
\end{tabular}

Bryophytes with $<5 \%$ frequency in microplots included 20 mosses: Antitrichia curtipendula, Dicranella heteromalla, Dicranum fuscescens, Dryptodon patens, Heterocladium procurrens, Isothecium stoloniferum, Mnium spinulosum, Oligotrichum parallelum, Plagiothecium undulatum, Pleurozium schreberi, Pohlia nutans, Polytrichastrum alpinum, Pseudoleskea stenophylla, Pseudotaxiphyllum elegans, Pterigynandrum filiforme, Racomitrium ericoides, Racomitrium sudeticum, Rhizomnium nudum, Rhytidiadelphus loreus, Rhytidiadelphus squarrosus; and 8 liverworts: Cephalozia bicuspidata, Diplophyllum plicatum, Geocalyx graveolens, Lepidozia reptans, Porella cordaeana, Scapania bolanderi, Scapania diplophylloides, Scapania scandica.

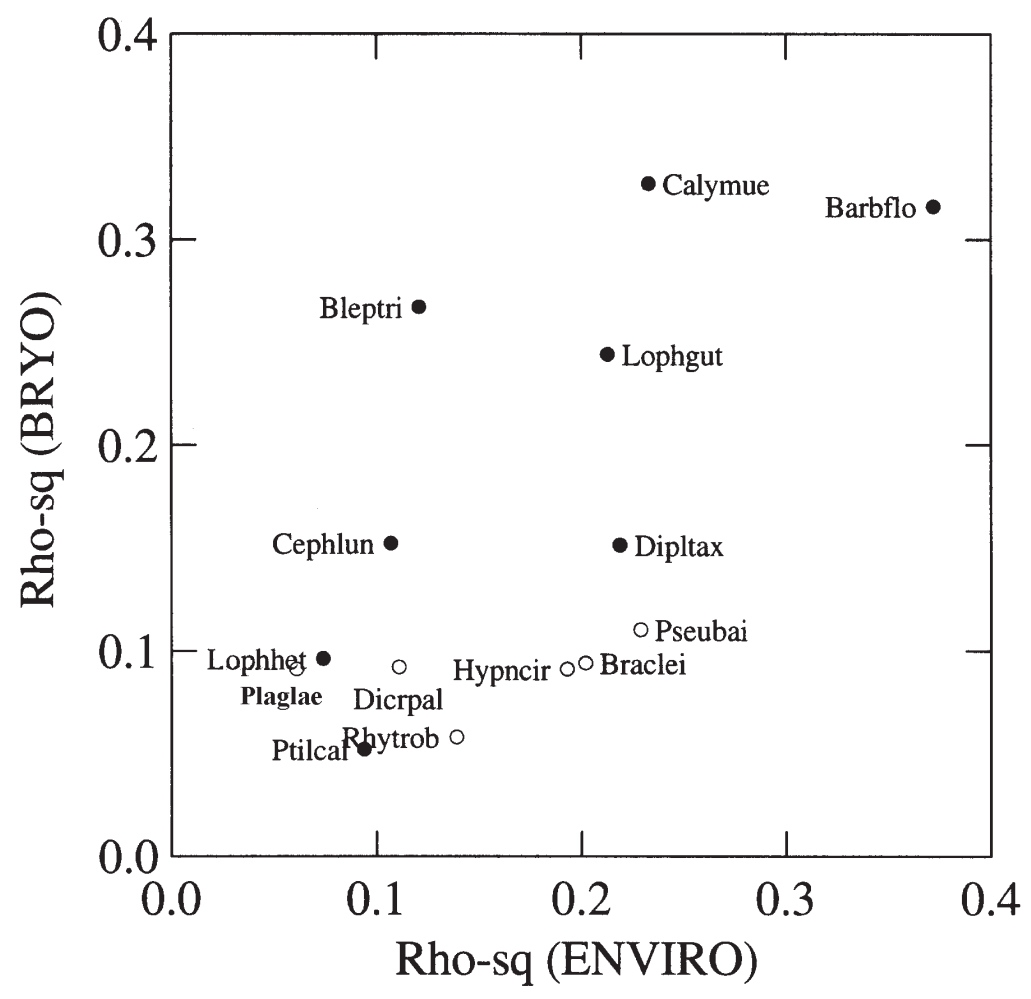

Figure 1. Summary of logistic regression models relating presence/absence of mosses (open circles) and liverworts (solid circles) to environmental variables (ENVIRO) and coverage of other bryophyte species (BRYO). Axes are Rho-squared values denoting overall strength of the predictive relationships. 
Table 2. Probabilities (p-values) from logistic regression models predicting the presence (+) or absence (-) of each bryophyte species in microplots from environmental variables*. Significant $p$-values $(\leq 0.05)$ are shown in bold.

\begin{tabular}{|c|c|c|c|c|c|c|c|c|c|c|c|c|c|c|}
\hline \multirow{2}{*}{$\begin{array}{l}\text { Predictor } \\
\text { variables }\end{array}$} & \multicolumn{2}{|c|}{ Braclei } & \multicolumn{2}{|c|}{ Dicrpal } & \multicolumn{2}{|c|}{ Hypncir } & \multicolumn{2}{|c|}{ Plaglae } & \multicolumn{2}{|c|}{ Pseubai } & \multicolumn{2}{|c|}{ Rhytrob } & \multicolumn{2}{|c|}{ Barbflo } \\
\hline & $\mathrm{p}$ & effect & $\mathrm{p}$ & effect & $\mathrm{p}$ & effect & $\mathrm{p}$ & effect & $\mathrm{p}$ & effect & $\mathrm{p}$ & effect & $\mathrm{p}$ & effect \\
\hline C:N Ratio & 0.01 & - & 0.17 & + & 0.00 & - & 0.04 & - & 0.75 & - & 0.17 & + & 0.30 & + \\
\hline Avg pH & 0.00 & - & 0.01 & - & 0.01 & - & 0.75 & + & 0.01 & - & 0.22 & - & 0.92 & + \\
\hline LFH & 0.07 & - & 0.24 & - & 0.05 & + & 0.63 & + & 0.02 & - & 0.08 & - & 0.03 & - \\
\hline Slope & 0.05 & + & 0.83 & - & 0.85 & - & 0.62 & + & 0.58 & - & 0.15 & - & 0.25 & - \\
\hline Aspect & 0.72 & + & 0.17 & - & 0.71 & - & 0.39 & - & 0.00 & + & 0.27 & - & 0.01 & - \\
\hline AvgCan & 0.21 & . & 0.01 & - & 0.30 & + & 0.43 & + & 0.12 & - & 0.42 & + & 0.03 & - \\
\hline AvgVasc & 0.89 & - & 0.27 & - & 0.59 & + & 0.08 & - & 0.83 & - & 0.52 & - & 0.04 & - \\
\hline HtVasc & 0.24 & - & 0.16 & + & 0.74 & - & 0.17 & + & 0.05 & + & 0.76 & + & 0.53 & + \\
\hline NumVasc & 0.15 & + & 0.88 & - & 0.00 & - & 0.59 & + & 0.11 & + & 0.64 & + & 0.14 & + \\
\hline NumSeed & 0.43 & + & 0.20 & + & 0.38 & + & 0.02 & + & 0.44 & - & 0.30 & - & 0.53 & - \\
\hline$\%$ EXH & 0.39 & + & 0.11 & + & 0.16 & + & 0.04 & + & 0.61 & - & 0.90 & + & 0.49 & - \\
\hline$\%$ CRS & 0.86 & + & 0.86 & + & 0.44 & - & 0.27 & + & 0.12 & + & 0.15 & - & 0.17 & - \\
\hline$\% W O O D$ & 0.45 & + & 0.09 & - & 0.70 & + & 0.28 & - & 0.07 & $\cdot$ & 0.00 & - & 0.35 & - \\
\hline Predictor & & trii & Cal. & mue & Cep & alun & & Itax & & hhet & Lop & hgut & Ptil & cal \\
\hline variables & $\mathrm{p}$ & effect & $\mathrm{p}$ & effect & $\mathrm{p}$ & effect & $\mathrm{p}$ & effect & $\mathrm{p}$ & effect & $\mathrm{p}$ & effect & $\mathrm{p}$ & effect \\
\hline C:N Ratio & 0.82 & + & 0.34 & - & 0.53 & + & 0.41 & - & 0.20 & - & 0.75 & + & 0.21 & - \\
\hline Avg pH & 0.84 & - & 0.94 & - & 0.19 & - & 0.54 & + & 0.53 & + & 0.37 & + & 0.00 & - \\
\hline LFH & 0.34 & - & 0.31 & - & 0.75 & + & 0.40 & - & 0.68 & + & 0.05 & - & 0.14 & - \\
\hline Slope & 0.18 & + & 0.53 & + & 0.14 & + & 0.09 & + & 0.59 & + & 0.39 & + & 0.41 & + \\
\hline Aspect & 0.45 & - & 0.02 & - & 0.19 & . & 0.34 & - & 0.05 & + & 0.08 & - & 0.66 & + \\
\hline AvgCan & 0.69 & - & 0.21 & - & 0.39 & + & 0.03 & - & 0.14 & + & 0.00 & - & 0.28 & + \\
\hline AvgVasc & 0.94 & + & 0.73 & + & 0.33 & + & 0.46 & - & 0.93 & + & 0.62 & + & 0.59 & - \\
\hline HtVasc & 0.81 & - & 0.62 & + & 0.54 & + & 0.05 & + & 0.24 & + & 0.85 & - & 0.49 & + \\
\hline NumVasc & 0.44 & + & 0.09 & + & 0.61 & . & 0.26 & - & 0.46 & + & 0.44 & + & 0.91 & - \\
\hline NumSeed & 0.95 & + & 0.50 & + & 1.00 & - & 0.40 & - & 0.17 & + & 0.23 & + & 0.20 & + \\
\hline$\%$ EXH & 0.00 & + & 0.00 & + & 0.00 & + & 0.79 & - & 0.02 & + & 0.85 & - & 0.03 & + \\
\hline$\%$ CRS & 0.70 & - & 0.00 & - & 0.41 & - & 0.07 & - & 0.13 & - & 0.05 & - & 0.03 & + \\
\hline \%WOOD & 0.01 & + & 0.79 & - & 0.39 & + & 0.01 & - & 0.63 & + & 0.59 & + & 0.00 & + \\
\hline
\end{tabular}

* Variables shown include carbon to nitrogen ratio (C:N ratio); average pH (Avg pH); LFH depth in cm (LFH); slope in degrees (Slope); aspect in degrees from north (Aspect); average canopy coverage (AvgCan); average vascular plant coverage (Avgvasc); maximum vascular plant height ( $\mathrm{HtVasc}$ ); number of species of vascular plants (Numvasc); number of conifer seedlings (NumSeed); availability (i.e., coverage) of substrata (\%EXH, \%CRS, \%WOOD).

The pattern of significance among soil variables (C:N ratio, $\mathrm{pH}, \mathrm{LFH}$ ) for mosses suggests that they may be more sensitive to changes in soil chemistry than are liverworts. Where significant, average canopy cover and average cover of vascular plants show negative predictions of bryophyte occurrence.

When the coverages of other bryophyte species are used as predictors, most of the significant relationships are positive (Table 3). Two exceptions are the reciprocal negative predictions between Hypnum circinale and Barbilophozia floerkei, and the negative prediction of coverage of Calypogeia muelleriana for Rhytidiopsis robusta. Both cases involve a moss-liverwort relationship, and suggest that microhabitat distinctions for some species may be pronounced.

The predominance of positive relationships between species occurrences and the coverages of other species suggests that interspecific facilitation among terrestrial bryophytes may have an important influence on distribution patterns in subalpine forests. That is, bryophyte species, once established, may facilitate the establishment of other bryophytes. This example of positive feedback among bryophytes is similar to those described for plantplant and plant-soil interactions in other ecosystems (Perry et al. 1989, Cox and Larson 1993, Rietkerk and van de Koppel 1997). 
Table 3. Probabilities (p-values) from logistic regression models predicting the presence $(+)$ or absence (-) of each bryophyte species in microplots from percent coverages of other bryophyte species. Significant p-values $(\leq 0.05)$ are shown in bold.

\begin{tabular}{|c|c|c|c|c|c|c|c|c|c|c|c|c|c|c|}
\hline \multirow{2}{*}{$\begin{array}{l}\text { Predictor } \\
\text { variables }\end{array}$} & \multicolumn{2}{|c|}{ Braclei } & \multicolumn{2}{|c|}{ Dicrpal } & \multicolumn{2}{|c|}{ Hypncir } & \multicolumn{2}{|c|}{ Plaglae } & \multicolumn{2}{|c|}{ Pseubai } & \multicolumn{2}{|c|}{ Rhytrob } & \multicolumn{2}{|c|}{ Barbflo } \\
\hline & $\mathrm{p}$ & effect & $\mathrm{p}$ & effect & $p$ & effect & $p$ & effect & $\mathrm{p}$ & effect & $\mathrm{p}$ & effect & $\mathrm{p}$ & effect \\
\hline Braclei & & & 0.26 & - & 0.84 & + & 0.92 & + & 0.30 & - & 0.38 & + & 0.71 & - \\
\hline Dicrpal & 0.02 & + & & & 0.82 & - & 0.26 & + & 0.00 & + & 0.73 & + & 0.00 & + \\
\hline Hypncir & 0.21 & - & 0.25 & + & & & 0.03 & + & 0.49 & - & 0.60 & - & 0.00 & - \\
\hline Plaglae & 0.57 & - & 0.10 & - & 0.73 & + & & & 0.52 & . & 0.15 & - & 0.21 & - \\
\hline Pseubai & 0.39 & + & 0.93 & - & 0.40 & - & 0.10 & - & & & 0.61 & + & 0.49 & - \\
\hline Rhytrob & 0.32 & + & 0.14 & + & 0.11 & - & 0.56 & - & 0.06 & + & & & 0.73 & - \\
\hline Barbflo & 0.21 & - & 0.43 & + & 0.00 & - & 0.27 & - & 0.06 & + & 0.03 & + & & \\
\hline Bleptri & 0.94 & + & 0.96 & - & 1.00 & + & 0.45 & - & 0.37 & + & 0.86 & + & 0.81 & + \\
\hline Calymue & 0.00 & + & 0.55 & + & 0.27 & - & 0.19 & + & 0.45 & - & 0.01 & - & 0.07 & + \\
\hline Cephlun & 0.00 & + & 0.15 & + & 0.04 & + & 0.47 & - & 0.12 & - & 0.30 & + & 0.66 & + \\
\hline Dipltax & 0.82 & + & 0.33 & - & 0.48 & + & 0.98 & - & 0.26 & + & 0.18 & + & 0.99 & - \\
\hline Lophhet & 0.42 & + & 0.05 & + & 0.27 & + & 0.02 & + & 0.75 & - & 0.21 & + & 0.81 & - \\
\hline Lophgut & 0.89 & + & 0.06 & + & 0.33 & - & 0.08 & - & 0.11 & - & 0.82 & + & 0.02 & + \\
\hline Ptilcal & 0.53 & + & 0.30 & + & 0.05 & + & 0.07 & + & 0.17 & - & 0.18 & - & 0.67 & + \\
\hline Predictor & \multicolumn{2}{|c|}{ Bleptri } & \multicolumn{2}{|c|}{ Calymue } & \multicolumn{2}{|c|}{ Cephlun } & \multicolumn{2}{|c|}{ Dipltax } & \multicolumn{2}{|c|}{ Lophhet } & \multicolumn{2}{|c|}{ Lophgut } & \multicolumn{2}{|c|}{ Ptilcal } \\
\hline variables & $\mathrm{p}$ & effect & $\mathrm{p}$ & effect & $\mathrm{p}$ & effect & $p$ & effect & p & effect & p & effect & p & effect \\
\hline Braclei & 0.38 & - & 0.31 & - & 0.39 & - & 0.37 & - & 0.10 & - & 0.44 & - & 0.88 & - \\
\hline Dicrpal & 0.21 & + & 0.95 & + & 0.78 & - & 0.35 & + & 0.90 & + & 0.00 & + & 0.53 & + \\
\hline Hypncir & 0.01 & + & 0.95 & + & 0.06 & + & 0.08 & - & 0.00 & + & 0.48 & - & 0.37 & + \\
\hline Plaglae & 0.18 & + & 0.00 & + & 0.86 & - & 0.66 & + & 0.08 & + & 0.06 & + & 0.98 & - \\
\hline Pseubai & 0.35 & - & 0.60 & . & 0.67 & - & 0.65 & - & 0.35 & - & 0.46 & - & 0.32 & - \\
\hline Rhytrob & 0.14 & + & 0.25 & + & 0.33 & + & 0.55 & - & 0.46 & - & 0.50 & + & 0.63 & + \\
\hline Barbflo & 0.01 & + & 0.93 & + & 0.01 & + & 0.66 & + & 0.14 & - & 0.05 & + & 0.33 & + \\
\hline Bleptri & & & 0.11 & + & 0.30 & + & 0.92 & + & 0.31 & + & 0.00 & + & 0.17 & + \\
\hline Calymue & 0.02 & + & & & 0.39 & + & 0.00 & + & 0.16 & - & 0.00 & + & 0.19 & - \\
\hline Cephlun & 0.04 & + & 0.05 & + & & & 0.14 & + & 0.04 & + & 0.02 & + & 0.05 & + \\
\hline Dipltax & 0.97 & + & 0.05 & + & 0.45 & + & & & 0.27 & + & 0.05 & + & 0.51 & - \\
\hline Lophet & 0.00 & + & 0.73 & . & 0.01 & + & 0.03 & + & & & 0.88 & + & 0.45 & + \\
\hline Lophgut & 0.04 & + & 0.07 & + & 0.72 & - & 0.05 & + & 0.17 & - & & & 0.21 & - \\
\hline Ptilcal & 0.72 & + & 0.22 & - & 0.71 & + & 0.50 & - & 0.74 & - & 0.06 & - & & \\
\hline
\end{tabular}

The results for both types of LR models can be compared using rho-squared values to elucidate which factors (environment and/or coverages of other bryophytes) most influence the occurrence of individual species. Fig. 1 illustrates the rho-squared values associated with bryophyte species occurrence in relation to the type of predictor variables used. Species that have a rho-squared value $>0.2$ on one or both axes are more predictably (i.e., less randomly) distributed. These species must have a narrower range of tolerance because they occur only where there is a specific set of environmental conditions, and/or where other bryophytes are established.

Bryophytes with a rho-squared value of $>0.2$ on the $x$-axis, but $<0.2$ on the $y$-axis, can be characterized as having strong relationships with environmental variables (e.g., particular substratum affinities or habitat requirements) that may restrict their fine scale distribution; inter- active associations with other bryophytes are less important. Conversely, if the occurrence of a species can only be predicted from the coverages of other bryophytes, facilitation may be influencing distribution patterns. Blepharostoma trichophyllum is the only species that has a high rho-squared value on the $y$-axis alone. LR results (Table 3) demonstrate that the occurrence of this species is positively associated with the increased coverage of many of the other species.

Bryophytes that have a rho-squared value $<0.2$ on both axes cannot be successfully predicted from environmental variables or from the coverage of other bryophytes in microplots; thus, they are more randomly distributed. These species are inferred to have a wider range of physiological tolerance because they occur over a broader range of environmental conditions and associations with other species. 


\section{Management implications}

Of the fourteen most frequent terrestrial bryophytes in this study, five cannot be successfully predicted from environmental factors and the cover of other bryophytes. Because these species are present in a variety of ecological situations, they are less likely to be permanently lost from an area in the event of environmental disturbance, such as logging, compared to species with closer ties to particular habitat conditions. For the latter group of species, the significant variables in Table 2 provided guidelines for determining which environmental factors are most influential at the microplot scale. Because of the differences in responses among species for microhabitat conditions, it is not expected that disturbance will affect all terrestrial bryophytes in subalpine forests in the same fashion. If, as suggested, facilitation is an important process in these forests, some species may be maintained only when habitat disturbance is minimized.

It is noteworthy that twenty-eight terrestrial bryophyte species did not occur frequently enough to be included in this analysis. The infrequency of these species suggests they may also require protection from habitat disturbance. Further study, however, is required of bryophytes associated with other types of substrata (i.e., epiphytes and epixylics) to determine which species are truly rare in subalpine forests.

Once "environmentally sensitive" bryophyte species have been characterized, LR analysis can be used secondarily to generate management guidelines for sustaining high bryophyte species diversity in subalpine forests. To build a model for applied usage from measurable variables, stepwise logistic regression analysis (a technique that adds or removes variables in order of their numerical importance in the model) may be more appropriate than the direct method of analysis used in this study. Although the stepwise method may be used to generate statistically similar models with the fewest number of predictive variables, the variables chosen by this procedure do not necessarily infer ecological importance. The significance of predictors in a LR model will depend on which variables are included. In consequence, there is more than one avenue for analysis and the results are open to interpretation.

It is concluded that LR is a useful statistical technique for examining species-habitat relationships at a fine scale. In this study, LR provided information about which variables most influence the occurrences of terrestrial bryophyte species in subalpine forests. LR analyses also provided insight into the relative importance of interactive processes in microscale distribution patterning. The use of habitat variables to predict the occurrence of bryophyte species may have practical applications in the development of forest management strategies that attempt to promote bryophyte diversity, or preserve rare species.

Acknowledgements: The authors thank Wilfred Schofield for his assistance with bryophyte identifications as well as financial support. We are grateful to Lyn Baldwin for collaboration during field sampling, and to Terry McIntosh, Jack Maze, Patrick Williston, and Andrew MacDougall for helpful comments on the manuscript

\section{References}

Carleton, T.J. 1990. Variation in terricolous bryophyte and macrolichen vegetation along primary gradients in Canadian boreal forests. J. Veg. Sci. 1: 585-594.

Carter, M.R. 1993. Soil Sampling and Methods of Analysis. Lewis, New York.

Cox, J.E. and D.W. Larson. 1993. Spatial heterogeneity of vegetation and environmental factors on talus slopes of the Niagara Escarpment. Can. J. Bot. 71: 323-332.

Gauch, H.G. 1982. Multivariate Analysis in Community Ecology: Cambridge Univ. Press, Cambridge.

Godfrey, J.D. 1977. The Hepaticae and Anthocerotae of Southwest British Columbia. Ph.D. Thesis, Univ. British Columbia

Hitchcock, C.L. and A. Cronquist. 1973. Flora of the Pacific Northwest; an illustrated manual. University of Washington Press, Seattle

Kenkel, N.C. and G.E. Bradfield. 1986. Epiphytic vegetation on Acer macrophyllum: a multivariate study of species-habitat relationships. Vegetatio 68: 43-53.

Lawton, E. 1971. Moss Flora of the Pacific Northwest. Hattori Botanical Laboratory, Nidiman, Japan.

McAlister, S. 1995. Species interactions and substrate specificity among log-inhabiting bryophyte species. Ecology 76: 21842195

Økland, R.H. 1994. Patterns of bryophyte associations at different scales in a Norwegian boreal spruce forest. J. Veg. Sci. 5: $127-$ 138.

Peck, J.E., S.A. Acker and W.A. McKee. 1995. Autecology of mosses in coniferous forests in the central western Cascades of Oregon. Northwest Sci. 69: 184-190.

Perry, D.A., M.P. Amaranthus, J.G. Borchers, S.L. Borchers and R.E. Brainerd. 1989. Bootstrapping in ecosystems. Biosci. 39: 230-237.

Pojar, J., K. Klinka and D.A. Demarchi. 1991. Mountain Hemlock Zone. In: D. Meidinger and J. Pojar (eds.), Ecosystems of British Columbia. B.C. Ministry of Forests, Victoria.

Rambo, T.R. and P.S. Muir. 1998. Forest floor bryophytes of Pseudotsuga menziesii - Tsuga heterophylla stands in Oregon: influences of substrate and overstory. Bryologist 101: 116-130.

Rietkerk, M. and J. van de Koppel. 1997. Alternate stable states and threshold effects in semi-arid grazing systems. Oikos 79 : 69-76.

Schofield, W.B. 1976. Bryophytes of British Columbia III: habitat and distributional information for selected mosses. Syesis 9 : 317-354.

Schofield, W.B. 1992. Some Common Mosses of British Columbia Royal British Columbia Museum, Victoria.

Soderstrom, L. 1993. Substrate preference in some forest bryophytes: a quantitative study. Lindbergia 18: 98-103.

Tabachnick, B.G. and L.S. Fidell. 1996. Using Multivariate Statistics. 3rd Edition. Harper-Collins, Northridge. 
Trexler, J.C. and J. Travis. 1993. Nontraditional regression analyses. Ecology 74: 1629-1637.

van de Rijit, C.W.C.J, L. Hazelhoff and C.W.P.M Blom. 1996. Vegetation zonation in a former tidal area: A vegetation-type response model based on DCA and logistic regression using GIS. J. Veg. Sci. 7: 505-518
Vitt, D.H., J.E. Marsh and R.B. Bovey. 1988. Mosses and Lichens of Northwest North America. Lone Pine, Edmonton. 